\title{
Synthesis and Properties of Novel T-type Nonlinear Optical Polyurethane Containing Tricyanovinylthienyl Group with Enhanced Thermal Stability of Dipole Alignment
}

\author{
You Jin Cho, Mi Sung Kim, and Ju-Yeon Lee* \\ Institute of Basic Science, Department of Chemistry, Inje University, Gimhae 621-749, Korea. ${ }^{*}$ E-mail: chemljy@inje.ac.kr \\ Received October 19, 2010, Accepted November 23, 2010
}

\begin{abstract}
A novel T-type polyurethane 7 containing 1-(2,5-dioxyphenyl)-2-(5-(1,2,2-tricyanovinyl)-2-thienyl)ethenes as NLO chromophores, which constitute part of the polymer backbone, was prepared. Polyurethane 7 is soluble in common organic solvents such as DMF and DMSO. It shows a thermal stability up to $270{ }^{\circ} \mathrm{C}$ from TGA thermogram with $T_{g}$ value obtained from DSC thermogram near $155^{\circ} \mathrm{C}$. The second harmonic generation (SHG) coefficient $\left(d_{33}\right)$ of poled polymer film at $1560 \mathrm{~nm}$ fundamental wavelength is $3.56 \times 10^{-9}$ esu. Polymer 7 exhibits a thermal stability even at $5^{\circ} \mathrm{C}$ higher than $T_{g}$, and no significant SHG decay is observed below $160^{\circ} \mathrm{C}$, which is acceptable for nonlinear optical device applications.
\end{abstract}

Key Words: Nonlinear optics, Polyurethane, Atomic force microscopy (AFM), Thermal stability, Second harmonic generation, Dipole alignment

\section{Introduction}

Recently nonlinear optical (NLO) materials have been extensively studied because of their potential applications in the field of photonic devices, including ultrafast optical switches, high-speed optical modulators, and high-density optical data storage media. ${ }^{1-6}$ The polymeric NLO materials seem to be superior because of their higher nonlinear optical activity, faster response time, low cost, and good processability to form electrooptic devices. A potential NLO polymer must contain highly polarizable conjugated dipolar electronic systems and they have to be mechanically very strong and thermally stable with high glass-transition temperature $\left(T_{g}\right)$. In the developments of NLO polymers for electro-optic device applications, stabilization of electrically induced dipole alignment is one of important criteria; in this context, two approaches to minimize the randomization have been proposed, namely the use of cross-linking ${ }^{7-10}$ and the utilization of high $T_{g}$ polymers such as polyimides. ${ }^{11-16}$

A polyurethane matrix forms extensive hydrogen bonding between urethane linkages, with increased rigidity preventing the relaxation of induced. ${ }^{17-18}$ Polyurethanes with a NLO chromophore, whose dipole moment is aligned transverse to the main chain backbone, show large second-order nonlinearity with good thermal stability. ${ }^{19-20}$ Physically cross-linked systems via hydrogen bonds have the advantages such as homogenity and good processability relative to chemically cross-linked systems, which suffer from significant optical loss and poor solubility. Recently we reported novel Y-type NLO polyurethanes with enhanced thermal stability of second harmonic generation. ${ }^{21-27}$ The resulting polymers exhibit high thermal stability of second harmonic generation (SHG), which stems from the stabilization of dipole alignment of the NLO chromophore. In this work reported here, we have prepared a novel polyurethane containing 1-(2,5-dioxyphenyl)-2-(5-(1,2,2-tricyanovinyl)-2-thienyl)ethane. groups as NLO chromophores. We selected the latter because they are expected to have large dipole moment. Furthermore, these 1-(2,5-dioxyphenyl)-2-(5-(1,2,2tricyanovinyl)-2-thienyl)ethene groups constitute a novel T-

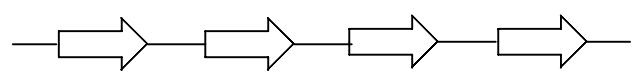

(a)

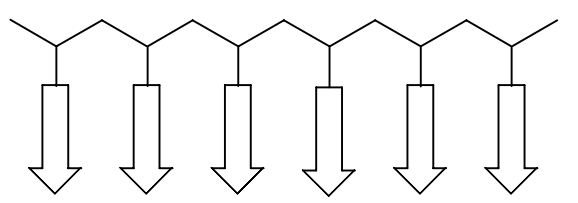

(b)

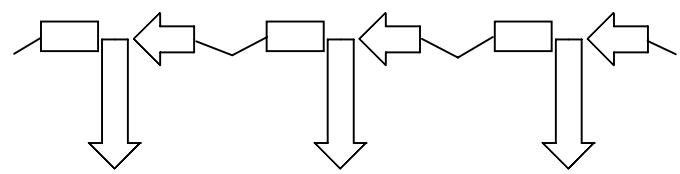

(c)

Figure 1. Schematic structures of NLO polymers with chromophores located (a) main-chain, (b) side-chain, and (c) main/side chain (T-type).

type NLO polyurthane (see Fig. 1c), in which the structure of NLO chromophores and this T-type NLO polyurethane is not described in the literature. Thus, we synthesized a new type of NLO polyurethane, in which the pendant NLO chromophores are components of the polymer backbone. This mid-type NLO polymer is expected to have the advantages of both main-chain and side-chain NLO polymers, namely stable dipole alignment and good solubility. After confirming the structure of the resulting polymer, we investigated its properties: solubility, $T_{\mathrm{g}}$, thermal stability, surface morphology of polymer films, second harmonic generation activity and relaxation of dipole alignment.

\section{Results and Discussion}

Synthesis and Characterization of Polymer. Compound 1 was prepared by the reaction of 2-chloroethyl vinyl ether with 2,5-dihydroxybenzaldehyde. Compound $\mathbf{2}$ was prepared by the bromination of 2-methylthiophene with $N$-bromosuccinimide. 

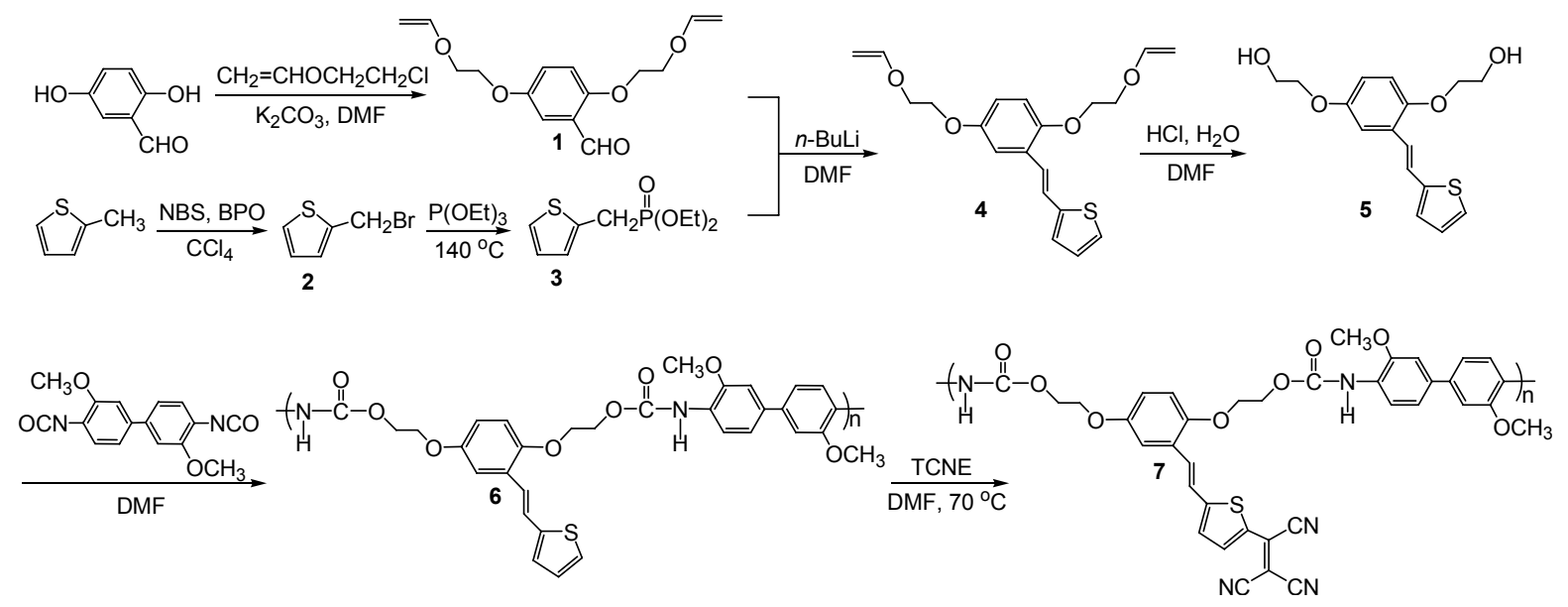

Scheme 1. Synthetic scheme and structure of polymer 7

Compound $\mathbf{3}$ was prepared by Arbuzov reaction from compound $\mathbf{2}$ and triethyl phosphite. Compound $\mathbf{4}$ was prepared by HornerEmmons olefination with compounds $\mathbf{1}$ and $\mathbf{3}$. Compound $\mathbf{5}$ was prepared by acid-catalyzed hydrolysis of 4 in DMF. Polyurethane $\mathbf{6}$ was prepared by the polyaddition reaction between diol 5 and 3,3'-dimethoxy-4,4'-biphenylenediisocyanate (DMBPI) in a dry DMF solvent. The polymerization yield was $88-90 \%$. Polymer 6 was reacted with tetracyanoethylene (TCNE) in anhydrous $\mathrm{DMF}^{18}$ to yield polyurethane 7 containing 1-(2,5-dioxyphenyl)-2-(5-(1,2,2-tricyanovinyl)-2-thienyl)ethene groups as NLO chromophores. The synthetic route for polymer 7 is presented in Scheme 1. The resulting polymer was purified by Soxhlet extraction for 2 days with methanol as a solvent.

The chemical structure of the polymer was identified using ${ }^{1} \mathrm{H}$ NMR, IR spectra, and elemental analysis. Elemental analysis results fit the polymer structure. ${ }^{1} \mathrm{H}$ NMR spectrum of the polymer had a signal broadening due to polymerization, but the chemical shifts are consistent with the proposed polymer structure. The signal at $8.54-9.17 \mathrm{ppm}$ assigned to the amine proton indicates the formation of urethane linkage. The IR spectrum of polymer 7 shows a strong absorption peak near $2219 \mathrm{~cm}^{-1}$ indicating the presence of nitrile group. The spectrum also shows a strong carbonyl peak near $1701 \mathrm{~cm}^{-1}$ indicating the presence of urethane bond. These results are consistent with the proposed structure, indicating that the tricyanovinyl groups are introduced well to the thiophene rings. The molecular weights were determined by GPC with polystyrene as the standard and THF as the eluent. The number average molecular weight $\left(M_{\mathrm{n}}\right)$ of the polymer 7, determined using GPC, is $16800\left(M_{\mathrm{w}} /\right.$ $\left.M_{\mathrm{n}}=1.91\right)$. The polymer 7 is soluble in common solvents such as acetone, DMF, and DMSO, but is not soluble in methanol and diethyl ether. The inherent viscosity is in the range 0.30 $0.32 \mathrm{dL} / \mathrm{g}$. Polymer 7 shows strong absorption near $549 \mathrm{~nm}$ due to the NLO chromophore 1-(2,5-dioxyphenyl)-2-(5-(1,2,2tricyanovinyl)-2-thienyl)ethene group.

The striking feature of this polymerization system is that it gives unprecedented T-type NLO polymers, in which the pendant NLO chromophores are part of the polymer backbone. These mid-type NLO polymers are expected to have the advan- tages of both main-chain and side-chain NLO polymers. Thus, we obtained a new type of NLO polyurethane with side-chain and main-chain characteristics. Having obtained well defined T-type polyurethane 7, we investigated its properties.

Thermal Properties of Polymer. The thermal behavior of the polymer was investigated using thermogravimetric analysis (TGA) and differential scanning calorimeter (DSC) to determine the thermal degradation pattern and glass transition temperature. The results are summarized in Table 1. The TGA thermogram of the polymer 7 is shown in Fig. 2. Polymer 7 has a thermal stability up to $270{ }^{\circ} \mathrm{C}$ according to its TGA thermogram. The $T_{g}$ value of the polymer 7 measured using DSC is near $155^{\circ} \mathrm{C}$. This $T_{g}$ value is higher than those of the polyurethanes containing dioxynitrostilbene, which is near $151{ }^{\circ} \mathrm{C}^{23}$ or dioxybenzylidenemalononitrile, which is near $146{ }^{\circ} \mathrm{C} .{ }^{24}$ However, the $T_{g}$ value is rather lower than that of the $\mathrm{Y}$-type polyurethane, which is near $163{ }^{\circ} \mathrm{C}^{27}$ The TGA and DSC studies show that the decomposition temperature of the polymer 7 is higher than that of poling temperature. This indicates that corona poling at 160 ${ }^{\circ} \mathrm{C}$ for a short term is feasible without damaging the NLO chromophore.

Film Morphology of Polymer. To induce noncentrosymmetric polar order, the spin-coated polymer films were coronapoled. As the temperature was raised to $160{ }^{\circ} \mathrm{C}, 6.5 \mathrm{kV}$ of corona voltage was applied and this temperature was maintained for $30 \mathrm{~min}$. The poling was confirmed from UV-visible absorption spectra. The UV-visible spectra of the polymer 7 before and after poling are presented in Fig. 3. After electric poling, the dipole moments of the NLO chromophores were aligned and the UV-visible absorption of polymer 7 exhibits a slight blue shift and a decrease in absorption due to birefringence. From the absorbance change, the order parameter of the poled film could be estimated, which is related to the poling efficiency. The estimated order parameter value $\Phi$ of polymer 7 is equal to $0.16\left(\Phi=1-\mathrm{A}_{1} / \mathrm{A}_{0}, \mathrm{~A}_{1}=0.7417, \mathrm{~A}_{0}=0.8809\right.$, where $\mathrm{A}_{0}$ and $\mathrm{A}_{1}$ are the absorbances of the polymer film before and after poling). For the purpose of investigating the surface morphology of polymer film, domain structures of NLO chromophores for the thinfilm samples were obtained using atomic force microscopy 


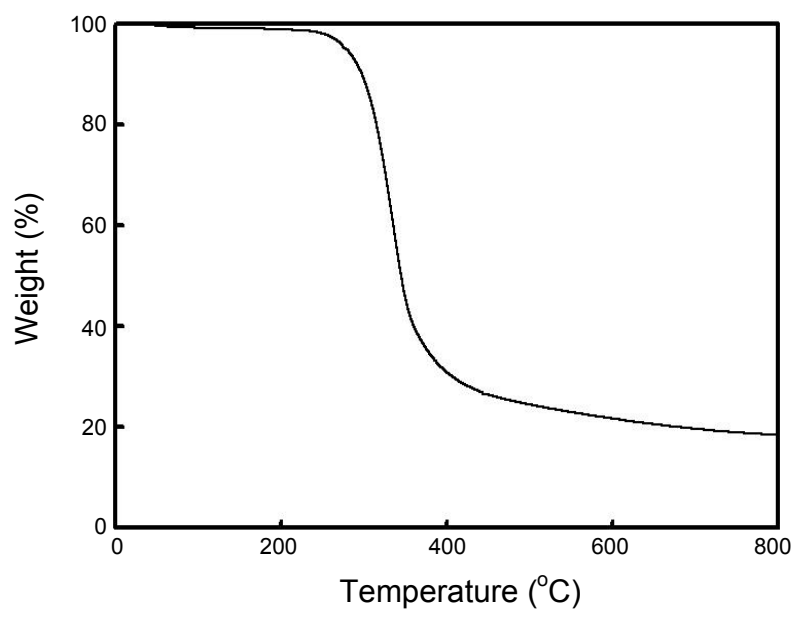

Figure 2. TGA thermogram of polymer 7 obtained at a heating rate of $10^{\circ} \mathrm{C} / \mathrm{min}$ under nitrogen.

Table 1. Thermal Properties of Polymer 7

\begin{tabular}{cccccc}
\hline & & \multicolumn{3}{c}{ Degradation temp, ${ }^{\circ} \mathrm{C}^{b}$} & Residue at \\
\cline { 3 - 5 } Polymer & \begin{tabular}{c}
$\left.T_{\mathrm{g}}{ }^{\circ} \mathrm{C}\right)$ \\
\cline { 3 - 5 }
\end{tabular} & $\begin{array}{c}5 \mathrm{wt} \%- \\
\text { loss }\end{array}$ & $\begin{array}{c}20 \mathrm{wt} \% 0^{-} \\
\text {loss }\end{array}$ & $\begin{array}{c}40 \mathrm{wt} \%{ }^{-} \\
\text {loss }\end{array}$ & $\begin{array}{c}800{ }^{\circ} \mathrm{C} \\
(\mathrm{wt} \%)^{b}\end{array}$ \\
\hline 7 & 155 & 277 & 315 & 335 & 18.4 \\
\hline
\end{tabular}

${ }^{a}$ Determined from DSC curves measured with a TA 2920 differential scanning calorimeter with a heating rate of $10^{\circ} \mathrm{C} / \mathrm{min}$ under nitrogen atmosphere. ${ }^{b}$ Determined from TGA curves measured with a TA Q50 thermogravimetric analyzer with a heating rate of $10{ }^{\circ} \mathrm{C} /$ min under nitrogen atmosphere.

(AFM). Fig. 4 shows AFM scans of a spin-coated film of polymer 7 before and after poling. AFM images show that the surface of the film sample is flat and smooth (Fig. 4a). However, this good quality film was dramatically changed after poling, resulting in numerous hills and valleys in the surface structure, which means that the NLO chromophores were aligned in the poling direction (see Fig. 4b).

Nonlinear Optical Properties of Polymer. The NLO properties of polymer were studied using the SHG method. The refractive index of the sample was measured using the optical transmission technique. ${ }^{28}$ The transmittance of thin film gives information on the thickness, refractive index and extinction coefficient. Thus, we could determine these parameters by analyzing the transmittance. SHG measurements were performed at a fundamental wavelength of $1560 \mathrm{~nm}$ using a mode locked NdYAG laser and optical parametric oscillator (OPO). In order to determine the microscopic second-order susceptibility of the polymer, the angular SHG dependence was recorded. Fig. 5 shows the angular dependence of SHG signal for a poled sample of polymer 7. The SHG values were compared with those obtained from a Y-cut quartz plate. To calculate the $d_{31}$ and $d_{33}$ values, both $s$-polarized and $p$-polarized IR laser were directed at the samples. SHG coefficients $\left(d_{33}\right)$ were derived from the analysis of measured Maker-fringes with the Pascal fitting program according to the literature procedure. ${ }^{29}$ Nonlinear optical properties of polymer 7 are summarized in Table 2 . The values of $d_{33}$ and $d_{31}$ for polymer 7 are $3.56 \times 10^{-9}$ and $1.12 \times 10^{-9} \mathrm{esu}$, respectively. This $d_{33}$ value is somewhat lower than that of the

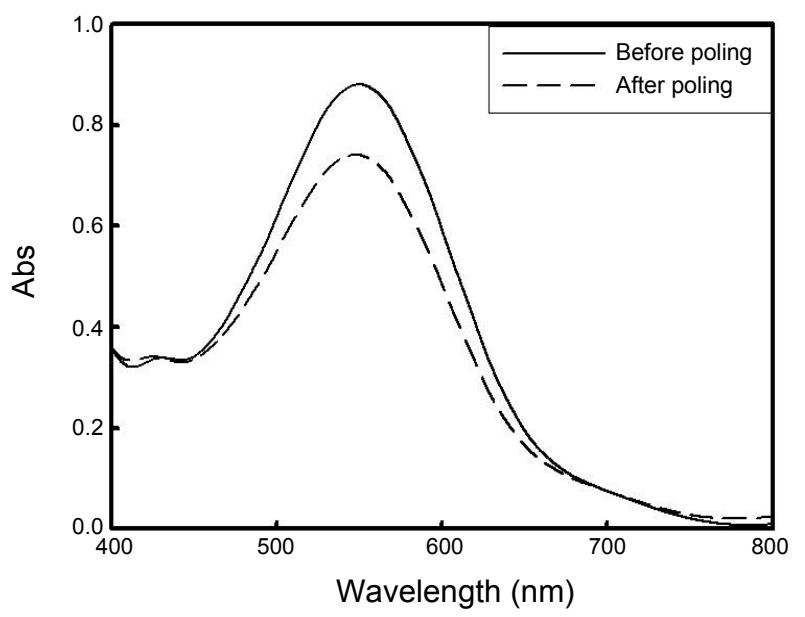

Figure 3. UV-visible absorption spectra of a film of polymer 7 before and after poling.

(a)

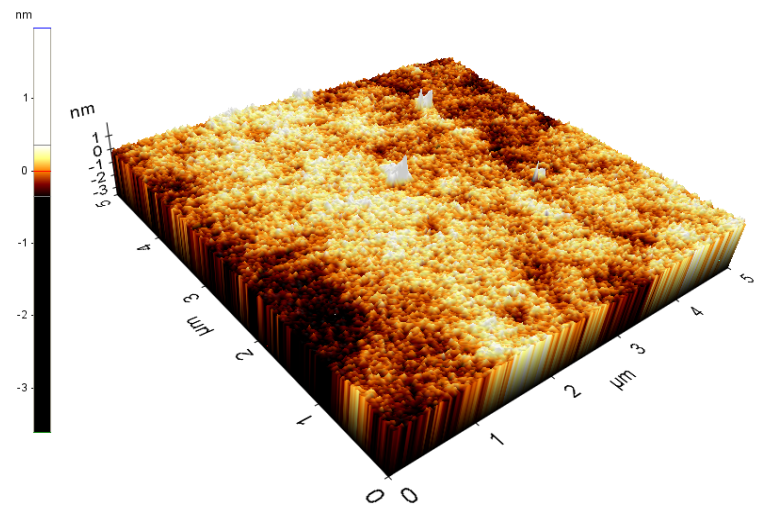

(b)

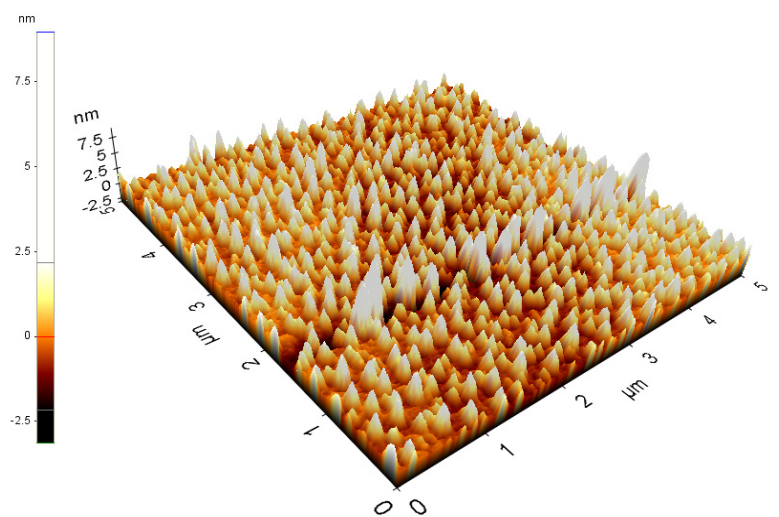

Figure 4. AFM images of spin-coated film of polymer 7: (a) before corona-poling; (b) after corona-poling.

Y-type polyurethane and other NLO polyurethanes. ${ }^{19}$ Since the second harmonic wavelength is at $780 \mathrm{~nm}$, which is not in the absorptive region of the resulting polyester, there is not resonant contribution to this $d_{33}$ value. In the isotropic model, the ratio of $d_{33} / d_{31}$ is predicted to be about 3 . Our $d_{33} / d_{31}$ value of 3.2 is in good agreement with the predicted value.

To evaluate the high-temperature stability of the polymers, we studied the temporal stability of the SHG signal. Fig. 6 shows the dynamic thermal stability study of the NLO activity of a film of polymer 7. To investigate the real time NLO decay of the 
Table 2. Nonlinear Optical Properties of Polymer 7

\begin{tabular}{ccccccc}
\hline Polymer & $\begin{array}{c}\lambda_{\max }{ }^{a} \\
(\mathrm{~nm})\end{array}$ & $\begin{array}{c}d_{33}{ }^{b} \\
(\mathrm{esu})\end{array}$ & $\Phi^{c}$ & $\begin{array}{c}d_{31}{ }^{b} \\
(\mathrm{esu})\end{array}$ & $\begin{array}{c}\text { film }^{\text {thickness }^{d}} \\
(\mu \mathrm{M})\end{array}$ & $n$ \\
\hline 7 & 549 & $3.56 \times 10^{-9}$ & 0.16 & $1.12 \times 10^{-9}$ & 0.48 & 1.524
\end{tabular}

${ }^{a}$ Polymer film after corona poling. ${ }^{b}$ SHG coefficients $\left(d_{33}\right)$ were derived from the analysis of measured Maker-fringes. ${ }^{29}{ }^{c}$ Order parameter $\Phi=1-\mathrm{A}_{1} /$ $\mathrm{A}_{0}$, where $\mathrm{A}_{0}$ and $\mathrm{A}_{1}$ are the absorbances of the polymer film before and after corona poling, respectively. ${ }^{d}$ Film thickness was determined using the optical transmission technique. ${ }^{28}$

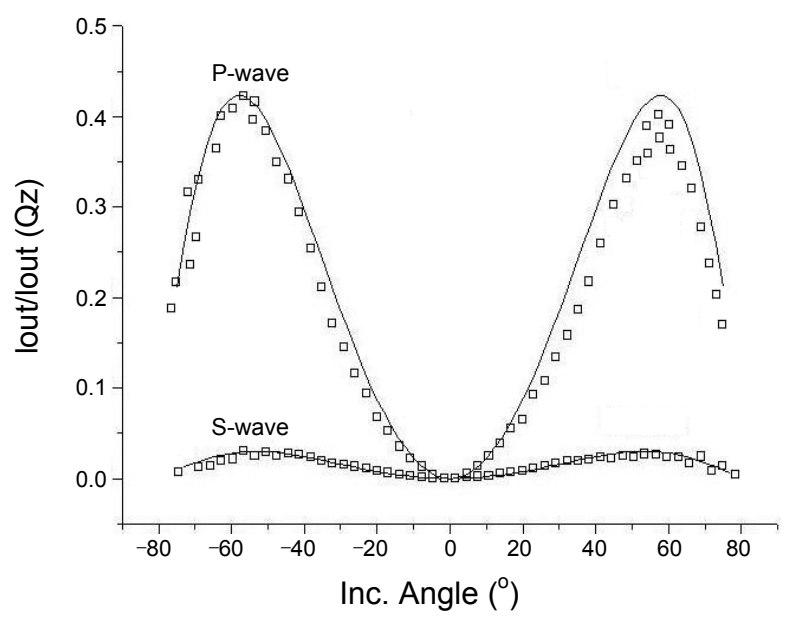

Figure 5. Angular dependence of SHG signal for a poled film of polymer 7.

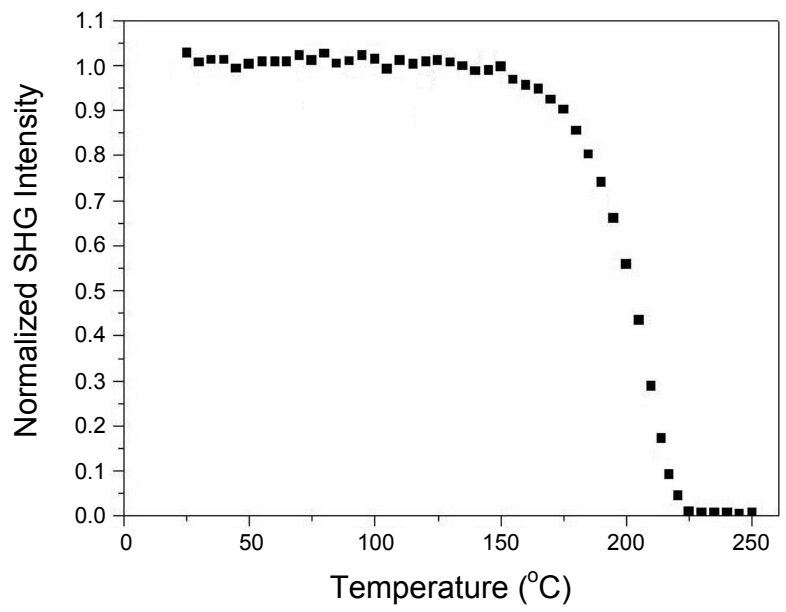

Figure 6. Normalized SHG signal of polymer 7 as a function of temperature at a heating rate of $4.5^{\circ} \mathrm{C} / \mathrm{min}$.

SHG signal of the poled polymer films as a function of temperature, in situ SHG measurements were performed at a heating rate of $4.5^{\circ} \mathrm{C} / \mathrm{min}$ from 30 to $250^{\circ} \mathrm{C}$. The polymer film exhibited a greater thermal stability even at $5^{\circ} \mathrm{C}$ higher than $T_{g}$, and no significant SHG decay was observed below $160^{\circ} \mathrm{C}$. In Fig. 7, we present the temporal stability of the polymer film in which there was no negligible decay of the SHG signal over hundreds of hours at $90^{\circ} \mathrm{C}$. In general, side-chain NLO polymers lose the

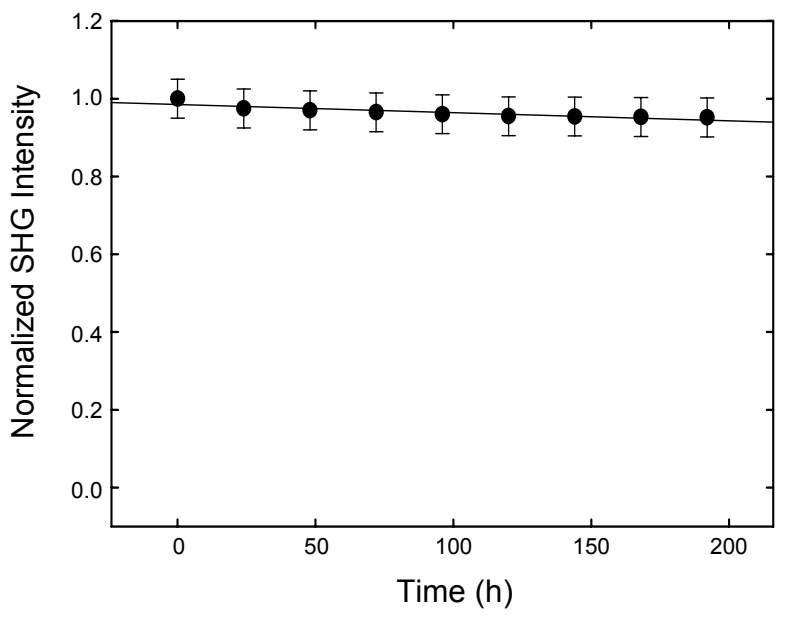

Figure 7. Normalized SHG signal of polymer 7 as a function of baking time at $90{ }^{\circ} \mathrm{C}$ in air.

thermal stability of dipole alignment around $T_{g}$. Stabilization of dipole alignment is a characteristic of main-chain NLO polymers. The high thermal stability of second harmonic generation of polymer $\mathbf{7}$ is due to the stabilization of dipole alignment of NLO chromophore, which stems from the partial main-chain character of the polymer structure and partly by hydrogen bonds between the neighboring urethane linkages. Thus, we obtained a new T-type of NLO polyurethane having the merits of both main-chain and side-chain NLO polymers, namely stable dipole alignment and good solubility.

\section{Conclusions}

A novel T-type NLO polyurethane 7 with pendant NLO chromophores as part of the polymer backbone was prepared and characterized. This T-type polymer 7 is soluble in common organic solvents and shows a thermal stability up to $270{ }^{\circ} \mathrm{C}$ with $T_{g}$ value around $155^{\circ} \mathrm{C}$. The SHG coefficient $\left(d_{33}\right)$ of corona-poled polymer film is $3.56 \times 10^{-9}$ esu. The structural feature of this polymer is that it exhibits a high SHG thermal stability even at $5^{\circ} \mathrm{C}$ higher than $T_{g}$, no SHG decay is observed below $160{ }^{\circ} \mathrm{C}$. This high thermal stability of optical nonlinearity stems from the stabilization of dipole alignment of the NLO chromophores, which constitute part of the polymer backbone, and partly by hydrogen bonds between the neighboring urethane linkages. We are now in the process of extending the polymerization system to the synthesis of other type of NLO polymers and the results will be reported elsewhere.

\section{Experimental Section}

Materials. Reagent-grade chemicals were purchased from Aldrich and purified by either distillation or recrystallization before use. 2-Methylthiophene, triethyl phosphite, $n$-butyllithium, 2-chloroethyl vinyl ether, $N$-bromosuccinimide and 2,5dihydroxybenzaldehyde were used as received. Tetracyanoethylene (TCNE) was purified by sublimation under vacuum. 3,3'-Dimethoxy-4,4'-biphenylenediisocyanate (DMBPI) was recrystallized from ethyl acetate. $N, N$-Dimethylformamide 
(DMF) was purified by drying with anhydrous calcium sulfate, followed by distillation under reduced pressure.

Measurements. Infrared (IR) spectra were obtained with a Shimadzu FT IR-8201PC infrared spectrophotometer. ${ }^{1} \mathrm{H}$ NMR spectra were obtained with a Varian $300 \mathrm{MHz}$ NMR spectrometer. UV-visible absorption spectra were obtained with a Shimadzu UV-3100S spectrophotometer. Elemental analyses were performed using a Perkin-Elmer $2400 \mathrm{CHN}$ elemental analyzer. $T_{\mathrm{g}}$ values were measured using a TA 2920 differential scanning calorimeter DSC in a nitrogen atmosphere. A TA Q50 thermogravimetric analyzer with a heating rate of $10{ }^{\circ} \mathrm{C} / \mathrm{min}$ up to $800{ }^{\circ} \mathrm{C}$ was used for the thermal degradation of polymers under nitrogen. The number-average molecular weight $\left(M_{\mathrm{n}}\right)$ and weight-average molecular weight $\left(M_{\mathrm{w}}\right)$ of the polymers were estimated using gel permeation chromatography (GPC; styragel HR5E4E columns; tetrahydrofuran (THF) solvent). AFM images were recorded with a Park Science Instrument Autoprobe CP, operated in a contact mode, which measures topography. Viscosity values were obtained using a CannonFenske viscometer.

Film Preparation and SHG Measurement. The polymer film was prepared from a $10 \mathrm{wt} \%$ DMF solution deposited on an indium-tin oxide (ITO) covered glass. Prior to film casting, the polymer solution was filtered through $0.45 \mu \mathrm{M}$ Teflon ${ }^{\circledR} \mathrm{mem}-$ brane filter. The film was spin cast at $60{ }^{\circ} \mathrm{C}$ in the range 1200 $1600 \mathrm{rpm}$. The films were dried for $48 \mathrm{~h}$ under vacuum at $60{ }^{\circ} \mathrm{C}$. The alignment of the NLO chromophore of the polymer was carried out by corona poling method. The poling was performed in a wire-to plane geometry under in situ conditions. The discharging wire to plane distance was $1.0 \mathrm{~cm}$. As the temperature was raised gradually to $5-10^{\circ} \mathrm{C}$ higher than $T_{\mathrm{g}}, 6.5 \mathrm{kV}$ of corona voltage was applied and kept at that temperature for $30 \mathrm{~min}$. The films were cooled to room temperature in the presence of the electric field. Finally, the electric field was removed. The refractive index of the sample was measured by the optical transmission technique. ${ }^{28}$ Second harmonic generation measurement was carried out one day after poling. The infrared fundamental radiation of the 1.56-micron was generated by using optical parametric oscillator (OPO) pumped by a Q-switched Nd:YAG laser operating at a repetition rate of $10 \mathrm{~Hz}$. The pulse width and beam diameter of the pump laser are $\sim 7-\mathrm{ns}$ and $6 \mathrm{~mm}$ in diameter, respectively. The OPO that we used has a well-established design. It consists of a $\mathrm{LiNbO}_{3}$ crystal $(12 \mathrm{~mm} \times 15 \mathrm{~mm} \times 50$ $\mathrm{mm}$ ) cut at $\sim 47 \mathrm{deg}$ for type-I angle phase matching inside a 70 $\mathrm{mm}$-long cavity with plane reflectors. The 3.346-micron output of the idler wave was eliminated by inserting a glass window in front of a sample. The electric field vector of the incident beam was either parallel (p-polarization) or perpendicular (s-polarization) to the plane of incidence. Only the p-polarized SH beam was made to enter a photomultiplier tube (PMT) by using a prism and a SH pass filter. An analyzer was used to confirm the polarization direction of the SH signal. A poled polymer film was mounted on the rotator coupled to a step motor. The output signals from the photodiode and PMT were detected as a function of the incident angle. A 3-mm-thick Y-cut quartz crystal (a piece of quartz plate whose plane is perpendicular to the crystalline $y$-axis and the thickness of the plate is $3 \mathrm{~mm}$. and $\mathrm{d}_{11}=0.3$ $\mathrm{pm} / \mathrm{V}$ ) was used as a reference for determining the relative in- tensities of the SH signals generated from the samples. The Maker Fringe pattern was obtained by measuring the SHG signal at $0.5^{\circ}$ intervals using a rotation stage. SHG coefficients $\left(d_{33}\right)$ were derived from the analysis of measured Maker-fringes. ${ }^{29}$

2,5-Di-(2'-vinyloxyethoxy)benzaldehyde (1). 2,5-Dihydroxybenzaldehyde (13.8 g, $0.10 \mathrm{~mol})$, anhydrous potassium carbonate $(82.9 \mathrm{~g}, 0.60 \mathrm{~mol})$, and 2-chloroethyl vinyl ether (26.6 g, $0.25 \mathrm{~mol}$ ) were dissolved in $400 \mathrm{~mL}$ of dry DMF under nitrogen. The mixture was heated in an oil bath kept at $80{ }^{\circ} \mathrm{C}$ for $15 \mathrm{~h}$ under nitrogen. The resulting solution was cooled to room temperature, diluted with $300 \mathrm{~mL}$ of water, and extracted with 300 $\mathrm{mL}$ of diethyl ether three times. The organic layer was washed with saturated aqueous sodium chloride solution, and dried with anhydrous magnesium sulfate. Rotary evaporation of diethyl ether gave crude product, which was recrystallized from 1-butanol yielded $24.5 \mathrm{~g}$ (88\% yield) of pure product $1 .{ }^{1} \mathrm{H}$ NMR $\left(\mathrm{CDCl}_{3}\right) \delta 3.98-4.34\left(\mathrm{~m}, 12 \mathrm{H}, 2 \mathrm{CH}_{2}=, 2-\mathrm{O}-\mathrm{CH}_{2}-\mathrm{CH}_{2}-\mathrm{O}-\right), 6.45-$ 6.58 (m, 2H, 2 =CH-O-), 6.92-6.99 (m, 1H, aromatic), 7.15-7.21 (m, 1H, aromatic), 7.33-7.36 (d, 1H, aromatic), $10.46(\mathrm{~s}, 1 \mathrm{H}$, -CHO). IR (KBr) 3096, 3075 (w, =C-H), 2941, 2882 (s, C-H), $1676(\mathrm{vs}, \mathrm{C}=\mathrm{O}), 1624(\mathrm{vs}, \mathrm{C}=\mathrm{C}) \mathrm{cm}^{-1}$.

2-Bromomethylthiophene (2). Compound 2 was prepared according to a literature procedure. ${ }^{18}$ 2-Methylthiophene $(9.82$ g, $0.10 \mathrm{~mol}), N$-bromosuccinimide $(17.80 \mathrm{~g}, 0.10 \mathrm{~mol})$, and benzoylperoxide $(0.24 \mathrm{~g}, 1.0 \mathrm{mmol})$ were dissolved in $80 \mathrm{~mL}$ of anhydrous carbon tetrachloride under a nitrogen atmosphere. The mixture was heated with vigorous stirring at $80^{\circ} \mathrm{C}$ for $3 \mathrm{~h}$ under nitrogen and then cooled to room temperature. The succinimide produced was filtered out with suction and water $(60 \mathrm{~mL})$ was added to the filtrate, which was extracted with diethyl ether $(60 \mathrm{~mL})$ three times. The organic layer was washed successively with saturated aqueous sodium bicarbonate $(60 \mathrm{~mL})$ and sodium chloride solution $(60 \mathrm{~mL})$, which was dried with anhydrous potassium carbonate. After evaporation of solvent by rotary evaporator, the crude product was purified by distillation under reduced pressure to yield $11.95 \mathrm{~g}$ (75\% yield) of $2 . \mathrm{Bp}=45-46$ ${ }^{\circ} \mathrm{C} / 5 \mathrm{mmHg} .{ }^{1} \mathrm{H} \mathrm{NMR}\left(\mathrm{CDCl}_{3}\right) \oint 4.75$ (s, 2H, $\left.-\mathrm{CH}_{2} \mathrm{Br}\right), 6.92$ (m, $1 \mathrm{H}$, aromatic), $7.09(\mathrm{~m}, 1 \mathrm{H}$, aromatic), 7.31 (m, 1H, aromatic). IR (KBr disc) 1673 (m, C=C), 1211 (s, C-S), 701 (vs, C-Br) $\mathrm{cm}^{-1}$.

Diethyl 2-Thienylmethylphosphonate (3). 2-Bromomethylthiophene $(5.97 \mathrm{~g}, 25 \mathrm{mmol})$ was added to triethyl phosphite $(4.49 \mathrm{~g}, 27 \mathrm{mmol})$. The resulting mixture was heated at $80{ }^{\circ} \mathrm{C}$ for $12 \mathrm{~h}$ and then cooled to room temperature and then ethyl bromide produced was distilled off and water $(60 \mathrm{~mL})$ was added to the filtrate, which was extracted with diethyl ether $(60 \mathrm{~mL})$ three times. The organic layer was washed with sodium chloride solution $(60 \mathrm{~mL})$, which was dried with anhydrous potassium carbonate. After evaporation of solvent by rotary evaporator, the obtained crude product was purified by distillation under reduced pressure to yield $5.39 \mathrm{~g}(92 \%$ yield $)$ of $3 . \mathrm{Bp}=95-96{ }^{\circ} \mathrm{C} / 2$ mmHg. ${ }^{1} \mathrm{H} \mathrm{NMR}\left(\mathrm{CDCl}_{3}\right) \delta 1.22\left(\mathrm{t}, 6 \mathrm{H}, 2-\mathrm{CH}_{3}\right), 3.31(\mathrm{~d}, 2 \mathrm{H}$, -Ar- $\mathrm{CH}_{2}$-PO-), 4.03 (m, 4H, 2 -O- $\mathrm{CH}_{2}-$ ), 6.91 (m, 2H, aromatic), 7.15 (m, 1H, aromatic). IR (KBr disc) $3123(\mathrm{w},=\mathrm{CH}), 2982(\mathrm{~m}$, $\mathrm{C}-\mathrm{H}), 1674(\mathrm{w}, \mathrm{C}=\mathrm{C}), 1247$ (s, $\mathrm{P}=\mathrm{O}) \mathrm{cm}^{-1}$. Anal. Calcd for $\mathrm{C}_{9-}$ $\mathrm{H}_{15} \mathrm{O}_{3}$ PS: C, 46.15; H, 6.45; S, 13.69. Found: C, 46.23; H, 6.49; $\mathrm{S}, 13.65$.

1-(2,5-Di-(2-vinyloxyethoxy)phenyl)-2-(2-thienyl)ethene (4). Under nitrogen at $0{ }^{\circ} \mathrm{C}, n$-butyllithium $(18.75 \mathrm{~mL}, 30 \mathrm{mmol}$, 
$1.6 \mathrm{~mol} \mathrm{~L}^{-1}$ in hexane) was added to the solution of compound $3(5.86 \mathrm{~g}, 25 \mathrm{mmol})$ in $10 \mathrm{~mL}$ of anhydrous DMF and stirred for $30 \mathrm{~min}$. To this reaction mixture was added compound 1 (5.56 $\mathrm{g}, 20 \mathrm{mmol}$ ) in $10 \mathrm{~mL}$ of anhydrous DMF slowly at $0{ }^{\circ} \mathrm{C}$ under nitrogen. The solution was stirred for $12 \mathrm{~h}$ at $0{ }^{\circ} \mathrm{C}$ under nitrogen. Water $(60 \mathrm{~mL})$ was added to the filtrate, which was extracted with diethyl ether $(60 \mathrm{~mL})$ three times. The organic layer was washed successively with saturated aqueous sodium bicarbonate $(60 \mathrm{~mL})$ and sodium chloride solution $(60 \mathrm{~mL})$, which was dried with anhydrous potassium carbonate. Evaporation of solvent by rotary evaporator gave crude product, which was purified by column chromatography (ethyl acetate $/ n$-hexane $=1 / 4$, vol $/ \mathrm{vol}$ ) to yield $5.24 \mathrm{~g}$ (74\% yield) of 4 . ${ }^{1} \mathrm{H}$ NMR (DMSO- $\left.d_{6}\right) \delta 3.96-$ $4.08\left(\mathrm{~m}, 6 \mathrm{H}, \mathrm{CH}_{2}=\right.$, $\left.-\mathrm{O}-\mathrm{CH}_{2}-\mathrm{CH}_{2}-\mathrm{O}-\right)$, 4.17-4.33 (m, 6H, $\mathrm{CH}_{2}=$, $-\mathrm{O}-\mathrm{CH}_{2}-\mathrm{CH}_{2}-\mathrm{O}-$ ), 6.54-6.66 (m, 2H, 2=CH-O-), 6.81-6.87 (q, $1 \mathrm{H},-\mathrm{CH}=), 6.97-7.01(\mathrm{~d}, 1 \mathrm{H},-\mathrm{CH}=), 7.05-7.16(\mathrm{~m}, 3 \mathrm{H}$, aromatic), 7.23-7.27 (d, $1 \mathrm{H}$, aromatic), 7.44-7.48 (d, $1 \mathrm{H}$, aromatic), 7.51-7.57 (d, 1H, aromatic). IR ( $\mathrm{KBr}$ disc) $3108(\mathrm{w},=\mathrm{C}-\mathrm{H})$, 2928, $2873(\mathrm{~m}, \mathrm{C}-\mathrm{H}), 1618(\mathrm{vs}, \mathrm{C}=\mathrm{C}) \mathrm{cm}^{-1}$. Anal. Calcd for $\mathrm{C}_{20^{-}}$ $\mathrm{H}_{22} \mathrm{O}_{4} \mathrm{~S}$ : C, 67.01; H, 6.19; S, 8.95. Found: C, 67.08; H, 6.25; $\mathrm{S}, 8.89$.

1-(2,5-Di-(2-hydroxyethoxy)phenyl)-2-(2-thienyl)ethene (5). Aqueous hydrochloric acid $\left(1.5 \mathrm{~mol} \mathrm{~L}^{-1}, 12 \mathrm{~mL}\right)$ was slowly added to a solution of compound $4(3.58 \mathrm{~g}, 10 \mathrm{mmol})$ in $30 \mathrm{~mL}$ of dry DMF with stirring under nitrogen at $0{ }^{\circ} \mathrm{C}$. The mixture was stirred at $0{ }^{\circ} \mathrm{C}$ for $5 \mathrm{~h}$ under nitrogen. The resulting solution was poured into $100 \mathrm{~mL}$ of ice water and stirred. The product obtained was separated by suction and washed with $30 \%$ aqueous ethanol. Thus obtained product was recrystallized from ethanol to give $2.69 \mathrm{~g}$ (yield $88 \%$ ) of 5. ${ }^{1} \mathrm{H}$ NMR (DMSO- $d_{6}$ )

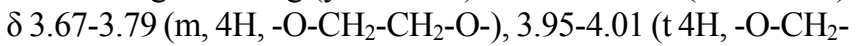
$\left.\mathrm{CH}_{2}-\mathrm{O}-\right), 4.87$ (t, 1H, -O-H), 4.94 (t, 1H, -O-H), 6.78-6.84 (q, $1 \mathrm{H},-\mathrm{CH}=)$, 6.94-6.97 (d, 1H, $-\mathrm{CH}=)$, 7.04-7.09 (m, 1H, aromatic), 7.15-7.24 (m, 3H, aromatic), 7.44-7.55 (q, 2H, aromatic). IR (KBr disc) 3266 (s, O-H), 2932, 2864 (m, C-H), 1602 (m, $\mathrm{C}=\mathrm{C}) \mathrm{cm}^{-1}$. Anal. Calcd for $\mathrm{C}_{16} \mathrm{H}_{18} \mathrm{O}_{4} \mathrm{~S}: \mathrm{C}, 62.72 ; \mathrm{H}, 5.92 ; \mathrm{S}$, 10.47. Found: C, 62.80; H, 5.96; S, 10.53 .

Synthesis of Polyurethane 6. A representative polyaddition reaction procedure was as follows. Dimethoxy-4,4'-biphenylenediisocyanate (DMBPI) $(2.96 \mathrm{~g}, 0.01 \mathrm{~mol})$ was added slowly to a solution of $3.06 \mathrm{~g}$ of diol $5(0.01 \mathrm{~mol})$ in $25 \mathrm{~mL}$ of anhydrous DMF. The resulting solution was degassed by a freeze-thaw process under vacuum and placed in an oil bath kept at $80{ }^{\circ} \mathrm{C}$. After heating $15 \mathrm{~h}$ with stirring the polymerization tube was opened and the viscous polymer solution was poured into 400 $\mathrm{mL}$ of cold water. The precipitated polymer was collected and re-precipitated from DMSO into methanol. The polymer was further purified by extraction in a Soxhlet extractor with methanol and dried under vacuum to give $5.43 \mathrm{~g}$ (90\% yield) of polymer 6. Inherent viscosity $\left(\eta_{\text {inh }}\right)=0.30 \mathrm{dL} / \mathrm{g}\left(\mathrm{c}=0.5 \mathrm{~g} \mathrm{dL}^{-1}\right.$ in DMSO at $25^{\circ} \mathrm{C}$ ). ${ }^{1} \mathrm{H}$ NMR (DMSO- $\left.d_{6}\right) \delta 3.79-3.92(\mathrm{~m}, 4 \mathrm{H}, 2$ $\mathrm{Ph}-\mathrm{O}-\mathrm{CH}_{2}-$ ), 3.99 (s, 6H, $\left.2-\mathrm{OCH}_{3}\right), 4.18-4.53$ (t, 4H, $2-\mathrm{CH}_{2-}$ OCO-), 6.88 (m, 1H, vinylic), 6.98 ( $\mathrm{m}, 1 \mathrm{H}$, vinylic), 7.12-7.36 (m, $8 \mathrm{H}$, aromatic), 7.51-7.57 (d, 1H, aromatic), 7.67-7.78 (q, $1 \mathrm{H}$, aromatic), 8.18-8.21 (d, 2H, aromatic), 8.54-8.63 (d, 1H, N-H), 8.95-9.06 (s, 1H, N-H). IR (KBr disc) 3397 (s, N-H), 2937 (m, $\mathrm{C}-\mathrm{H}), 1702(\mathrm{~s}, \mathrm{C}=\mathrm{O}), 1591(\mathrm{~s}, \mathrm{C}=\mathrm{C}) \mathrm{cm}^{-1}$. Anal. Calcd for $\left(\mathrm{C}_{32^{-}}\right.$ $\left.\mathrm{H}_{30} \mathrm{~N}_{2} \mathrm{O}_{8} \mathrm{~S}\right)_{n}$ : C, 63.77; H, 5.02; N, 4.65; S, 5.32. Found: C, 63.86;

\section{H, 5.09; N, 4.74; S, 5.41 .}

Synthesis of Polyurethane 7. A representative reaction procedure was as follows. Tetracyanoethylene $(1.28 \mathrm{~g}, 10 \mathrm{mmol})$ was added slowly to a solution of polymer $6(5.12 \mathrm{~g}, 8.5 \mathrm{mmol})$ dissolved in $15 \mathrm{~mL}$ of DMF with stirring at room temperature under nitrogen. The resulting solution was heated in an oil bath kept at $70^{\circ} \mathrm{C}$ for $20 \mathrm{~h}$ under a nitrogen atmosphere. The resulting polymerization solution was cooled to room temperature and poured into $400 \mathrm{~mL}$ of methanol. The precipitated polymer was collected and re-precipitated from DMSO into methanol. The polymer was further purified by extraction in a Soxhlet extractor with methanol and dried under vacuum to give $6.33 \mathrm{~g}(90 \%$ yield) of polymer 7 . Inherent viscosity $\left(\eta_{\text {inh }}\right)=0.31 \mathrm{dL} / \mathrm{g}(\mathrm{c}=0.5$ $\mathrm{g} \mathrm{dL}^{-1}$ in DMSO at $25^{\circ} \mathrm{C}$ ). ${ }^{1} \mathrm{H}$ NMR (DMSO- $\left.d_{6}\right) \delta 3.85-4.13(\mathrm{~m}$, $\left.8 \mathrm{H},-\mathrm{O}-\mathrm{CH}_{2-}, 2-\mathrm{OCH}_{3}\right), 4.26-4.65\left(\mathrm{~m}, 6 \mathrm{H},-\mathrm{O}-\mathrm{CH}_{2-}, 2-\mathrm{O}-\mathrm{CH}_{2-}\right.$ OCO-), 6.91-7.15 (m, 2H, -CH=CH-), 7.15-7.92 (m, 10H, aromatic), 8.25-8.32 (d, $1 \mathrm{H}$, aromatic), 8.54-8.72 (t, $1 \mathrm{H}, \mathrm{N}-\mathrm{H})$, 9.03-9.17 (s, 1H, N-H). IR (KBr disc) 3398 (s, N-H), 2940 (m, $\mathrm{C}-\mathrm{H}), 2219(\mathrm{~m}, \mathrm{CN}), 1701(\mathrm{~s}, \mathrm{C}=\mathrm{O}), 1592(\mathrm{~s}, \mathrm{C}=\mathrm{C}) \mathrm{cm}^{-1}$. Anal. Calcd for $\left(\mathrm{C}_{37} \mathrm{H}_{29} \mathrm{~N}_{5} \mathrm{O}_{8} \mathrm{~S}\right)_{n}$ : C, 63.15; H, 4.15; N, 9.95; S, 4.56 . Found: C, 63.27; H, 4.23; N, 9.86; S, 4.48.

Acknowledgments. This research was supported by Basic Science Research Program through the National Research Foundation of Korea (NRF) funded by the Ministry of Education, Science and Technology (No. 2010-0020951).

\section{References}

1. Marks, T. J.; Ratner, M. A. Angew. Chem. Int. Ed. Engl. 1995, 34, 155.

2. Lee, S. K.; Cho, M. J.; Jin, J.-I.; Choi, D. H. J. Polym. Sci. Part A: Polym. Chem. 2007, 45, 531.

3. Centore, R.; Riccio, P.; Carella, A.; Quatela, A.; Schutzmann, S.; Stella, F.; De Matteis, F. J. Polym. Sci. Part A: Polym. Chem. 2007, 45,2719

4. Li, Z.; Dong, S.; Li, P.; Li, Z.; Ye, C; Qin, J. J. Polym. Sci. Part A: Polym. Chem. 2008, 46, 2983.

5. Jin, F.-L.; Park, S.-J. Bull. Korean Chem. Soc. 2008, 29, 2521.

6. Shrestha, S. P.; Ghimire, R.; Nakarmi, J. J.; Kim, Y. S.; Shrestha, S.; Park, C. Y.; Boo, J. H. Bull. Korean Chem. Soc. 2010, 31, 112.

7. Zhang, C.; Wang, C.; Yang, J.; Dalton, L. R.; Sun, S.; Zhang, H.; Steier, W. H. Macromolecules 2001, 34, 235.

8. Kim, T.-D.; Luo, J.; Tian, Y.; Ka, J.-W.; Tucker, N. M.; Haller, M.; Kang, J.-W.; Jen, A. K.-Y. Macromolecules 2001, 39, 1676.

9. Liu, Y.-L.; Hsieh, C.-Y.J. Polym. Sci. Part A: Polym. Chem. 2006, $44,905$.

10. Moon, J. R.; Kim, B. S.; Kim, J.-H. Bull. Korean Chem. Soc. 2006, 27, 981.

11. Chen, T.; Jen, A. K. Y.; Cai, Y. Macromolecules 1996, $29,535$.

12. Saadeh, H.; Gharavi, A.; Yu, D.; Yu, L. Macromolecules 1997, 30, 5403.

13. Tsutsumi, N.; Morishima, M.; Sakai, W. Macromolecules 1998, 31,7764 .

14. Hoang, M, A.; Kim, M. H.; Cho, M. J.; Kim, K. H.; Kim, K. N.; Jin, J.-I.; Choi, D. H. J. Polym. Sci. Part A: Polym. Chem. 2008, 46, 5064.

15. Ryu, S.; Kim, J. H.; Lee, S. H.; Lee, M.-H. Bull. Korean Chem. Soc. 2008, 29, 1689.

16. Park, S. J.; Chae, S. W.; Rhee, J. M.; Kang, S. J. Bull. Korean Chem. Soc. 2010, 31, 2279

17. Moon, K. J.; Shim, H. K.; Lee, K. S.; Zieba, J.; Prasad, P. N. Macromolecules 1996, 29, 861. 
18. Woo, H. Y.; Lee, K. S.; Shim, H. K. Polym. J. 2000, 32, 8.

19. Tsutumi, N.; Matsumoto, O.; Sakai, W.; Kiyotsukuri, T.Macromolecules 1996, 29, 592.

20. Tsutumi, N.; Matsumoto, O.; Sakai, W. Macromolecules 1997, 30, 4584.

21. Lee, J.-Y.; Park, E.-J. J. Polym. Sci. Part A: Polym. Chem. 2002, 40, 1742

22. Lee, J.-Y.; Park, E.-J.; Lee, H.; Rhee, B. K. Polym. Bull. 2002, 48, 233.

23. Lee, J.-Y.; Bang, H.-B.; Park, E.-J.; Lee, W.-J.; Rhee, B. K.; Lee, S.
M. Polym. Intl. 2004, 53, 1838 .

24. Lee, J.-Y.; Bang, H.-B.; Park, E.-J.; Baek, C. S.; Rhee, B. K.; Lee, S. M. Syn. Met. 2004, 144, 159.

25. Lee, J.-Y.; Bang, H.-B.; Kang, T.-S.; Park, E.-J. Europ. Polym. J. 2004, 40, 1815.

26. Lee, J.-Y.; Bang, H.-B.; Baek, C. S. Syn. Met. 2005, 148, 161.

27. Jang, H.-N.; No, H. J.; Lee, J.-Y.; Rhee, B. K.; Cho, K.-H.; Choi, H.-D. Dyes Pigments 2009, 82, 209.

28. Cisneros, J. I. Appl. Opt. 1998, 37, 5262.

29. Herman, W. N.; Hayden, L. M. J. Opt. Soc. Am. B 1995, 12, 416. 